\title{
A critical review of the robustness of the UK government's Air Quality Plan and expected compliance dates
}

\author{
B. Williams, J. H. Barnes, T. J. Chatterton, E. T. Hayes \\ \& J. W. S. Longhurst \\ Air Quality Management Resource Centre, \\ University of the West of England, UK
}

\begin{abstract}
Globally, poor air quality is the most significant environmental health concern. Across Europe, 400,000 deaths were attributed to air pollution in 2012, whilst in the UK over 50,000 deaths per year are due to a combination of gaseous and particulate matter air pollution. The deadline for achieving the EU limit value for $\mathrm{NO}_{2}$ was the 1st of January 2010, yet the UK remains non-compliant in 38 of 43 zones and agglomerations. As a consequence, in April 2015, the government was ordered by the UK Supreme Court to draw up new air quality plans to achieve the EU limit values in the shortest time possible. In response the UK government consulted on a draft national air quality plan, which estimated compliance with the EU Air Quality Directive by 2020 in all zones and agglomerations except London (compliance by 2025). The plan introduces the concept of a Clean Air Zone (CAZ) to address the non-compliant zones but overall has significant weaknesses in many zones and agglomerations and compliance by 2020 (and 2025 in London) is considered to be overly optimistic. The plan's predictive models use vehicle emission factors that are not considered representative of actual driving conditions, and transparency in the data underlying vehicle fleet turnover calculations is lacking. The suitability of CAZ as a cornerstone of the plan is of particular concern. This contribution examines new evidence that challenges the robustness of the UK government's air quality plan. If air quality within the UK is to improve within the shortest time possible, significant improvements in the analysis and proposed solutions will be required.
\end{abstract}

Keywords: air pollution, Air Quality Plan, COPERT, real-world driving emissions, Defra, CAZ, compliance, EU limit values, $\mathrm{NO}_{x}, \mathrm{NO}_{2}$. 


\section{Introduction}

In 2016, the year that the UK's Clean Air Act turns sixty, the World Health Organisation declared air pollution as a public health emergency [1]. Globally, air pollution is responsible for 7 million premature deaths per year [2], equivalent to 1 in 8 of all recorded deaths. Across Europe, 400,000 deaths were attributed to air pollution in 2012, whilst in the UK over 50,000 deaths per year are due to a combination of gaseous (nitrogen dioxide and ozone) and particulate matter (PM) air pollution [3]. On a local authority scale, approximately $5 \%$ of all deaths in England and Wales are linked to air pollution, although as this percentage is based purely on PM, it is recognised as an underestimate [4].

In 1987, the World Health Organisation set health-based guidelines for particulate matter, nitrogen dioxide, ozone and sulphur dioxide, among others [5]. These guidelines provide absolute thresholds for health exposure. Based on these WHO guidelines, the EU Air Quality Framework Directive (96/62/EC) and subsequent daughter Directives were developed, which Member States were required to transpose by 1998 .

As a comparison between the EU limit values and the WHO guidelines, $88 \%$ of European citizens were exposed to $\mathrm{PM}_{10}$ levels deemed by the WHO to be hazardous to health whilst only $33 \%$ of citizens were in areas exposed to $\mathrm{PM}_{10}$ above national limit values. It could crudely be considered therefore that $55 \%$ of the EU population are in an air pollution 'no-man's land', where concentrations of air pollution are deemed harmful by the WHO but national strategies are not designed or calibrated to protect them from its harmful effects.

In the UK, the government established national air quality objectives in parallel with the EU limit values to be achieved by a combination of national measures supplemented with local action. Fine particulate matter $\left(\mathrm{PM}_{2.5}\right)$ was not included in national air quality objectives until the 2007 National Air Quality Strategy, and is only now being considered for introduction as a voluntary target for local authorities. Despite ever increasing layers of legislation since the Environment Act, from European directives through to national objectives [6], air pollution at a local level has not improved quickly enough.

The national $\mathrm{NO}_{2}$ objectives were due to be met by 31st December 2005, however by this deadline exceedences of the $\mathrm{NO}_{2}$ annual mean objective were still widespread and growing. The equivalent EU limit value for $\mathrm{NO}_{2}$ was to be achieved by 1 st January 2010 . At present, the UK remains non-compliant in 38 out of 43 zones and agglomerations for the $\mathrm{NO}_{2}$ limit value. After a lengthy legal campaign by the legal practice ClientEarth (http://www.dev.clientearth.org/), spanning national and international courts, in April 2015 the UK government was ordered by the UK Supreme Court to draw up new air quality plans to address air pollution in the UK. The Supreme Court emphasised the need for 'immediate action' [7]. The air quality plans were submitted to the European Commission in December 2015 and a decision on its robustness has not been made as of May 2016. 


\section{The Air Quality Plan}

The aim of the Air Quality Plan is to comply with the Supreme Court's order for immediate action to address poor air quality in the UK and to achieve compliance with EU limits as soon as possible. The plan was presented as three key documents. These consisted of an overview document that identifies what is required, how it is to be achieved and expected compliance dates, a technical report outlining methodologies, data and assumptions used in modelling, and a third document outlining strategies for a reduction in air pollution across national, devolved and local areas [8]. This paper largely examines the assumptions and arguments presented within the technical report.

A number of critical assumptions are made throughout the plan, each of which could have a substantial effect on likely compliance dates. Integrating assumptions into modelling exercises is a requirement for projecting future scenarios, however such data should be comprised of the most up to date and relevant information. Assumptions made within the Plan include those regarding vehicle emission factors, vehicle fleet turnover and the likely impact of the introduction of realworld emission factors, each of which can have an impact on the modelling outcomes. Key assumptions relating to each stage are discussed below preceded by a brief review of the consultation process used by Defra to shape the final AQP.

\subsubsection{The Defra consultation process}

As part of the process of developing a final AQP, Defra issued the AQP as a draft and made the document available for public consultation. In doing so, a number of issues relating to its openness and transparency were made by numerous stakeholders. In order to determine the key concerns amongst stakeholders with regards to the Plan, Barnes [9] obtained contact details for 85 of the 232 consultation respondents and from this obtained copies of 20 responses directly by email request and a further 23 via other sources, e.g. trade press, web searches and personal communication. These 43 responses were systematically reviewed.

Of the 43 responses reviewed, it was found that 19 (44\%) commented on the consultation process including the lack of available technical data, whilst $22(51 \%)$ expressed concerns about the model predictions; 16 (37\%) commented on both. A summary of the responses under these themes is presented below:

- The transparency and adequacy of the consultation process

- Evidence Annex inadequate to substantiate the consultation document.

- Absence of Technical Report rendered the draft air quality plan incomplete and undermined respondents' ability to comment.

- Online form too prescriptive to facilitate open responses.

- Timing of the consultation precluded significant revision of plans prior to submission.

- Inadequate detail on implementation, timing and impact of actions.

- The robustness of the modelling and supporting data

- 2013 baseline ignores developments that have worsened air quality in the interim.

- Real-world representativeness of COPERT emission factors criticised. 
- CAZ vehicle classes not representative of local authority exceedence areas' fleet composition.

- Four-year fleet turnover and uptake of ULEVs queried due to the recession.

- Resolution of streamlined PCM too coarse to capture local exceedences.

- Modelled $\mathrm{NO}_{2}$ validated against background AURN monitoring sites.

- Plan refers to discontinued (and incorrectly sited) roadside AURN monitors.

- Geographical inconsistencies between local authorities and modelled zones and agglomerations.

This independent review of consultation responses demonstrates that concerns relating to the transparency and adequacy of the consultation process and the accuracy of the model predictions were widely held. Of note, no reference was made regarding the transparency and adequacy the Summary Report of Consultation [10], including the two sections of the Report that summarise common themes raised and the Government's responses to issues raised. Barnes noted that the reasons for this omission are unclear, but the failure to report and acknowledge these widely expressed concerns suggests that these may have been overlooked by Defra in the preparation of the Final Air Quality Plan. A number of these concerns are discussed below.

\subsection{Assessing the robustness of the assumptions}

Stage 1 assumptions are those that are made of data prior to any modelling exercise. Within the UK, compliance is determined as a result of modelling using the Pollution Climate Mapping Model (PCM). As noted by Defra within the AQP, 'The Pollution Climate Mapping (PCM) model is a collection of models designed to fulfil part of the UK's EU Directive (2008/50/EC) requirements to report on the concentrations of particular pollutants in the atmosphere' [11]. The model is updated annually and for each road link there is a background concentration value and a roadside concentration value. Modelling was undertaken using a streamlined version of the PCM (SL-PCM) within the AQP The SL-PCM is limited in several areas compared to the full PCM, for example PCM can estimate the impact of changes in emissions from a range of sources, such as large and small point sources (e.g. power stations, airports) and transport, whereas SL-PCM focuses purely on transport emissions [12]. Assumptions of emission factors, fleet dynamics and future projections will all impact the outputs from these models and are set out and discussed below.

\subsubsection{Current emission factors}

Emission factors are rates of pollutant emissions for specified year, road type, vehicle speed, and vehicle fleet composition. Emission factors are used to assess the contribution of vehicle emissions in air quality analyses. As set out within the Air Quality Plan, the emission factors used in modelling using the StreamlinedPollution Climate Mapping model are derived from COPERT v4.11. COPERT is a software tool used to calculate air pollutant and greenhouse gas emissions from 
road transport and its development is coordinated by the European Environment Agency (EEA) (http://emisia.com/products/copert-4). Defra modelling within the AQP uses COPERT 4 emission factors which assume emissions from Euro 6 cars are 2.8 times higher than the EU standard, based on testing a small selection (ca. 6 cars) of early models in 2013.

Analysis by TNO [13] suggests that the COPERT vehicle emission factors for EURO 6 vehicles (which are unlikely to dominate the UK fleet until at least 2025) are too low and likely to be between $30-50 \%$ higher for urban driving conditions.

Emissions Analytics (an independent vehicle emission measurement and analysis organisation based in the UK) have demonstrated that this is an underestimate and consider the more likely emission factor to be ca. 3.5 as an average across urban, rural and motorway driving cycles [14]. Williams reviewed the literature on real-world emission testing studies and concluded that vehicle emissions from Euro 6 vehicles were on average 5-7 times greater than type approval results suggested [15].

In light of claims that a number of vehicle manufacturers, particularly Volkswagen, had achieved compliance with type approval tests in the USA through the use of defeat devices, the Department for Transport undertook an investigation into real-world vehicle emissions. The analysis focused on ca. $75 \%$ of top selling diesel vehicles in the UK and found that that real-world vehicle emissions are on average six times higher than type approval limits for the newest Euro 6 vehicles.

\subsubsection{Real-world driving}

Of particular relevance to the air pollution debate is the introduction in 2017 by the European Commission of a new World Light-Duty Test Protocol (WLTP) which will replace the existing New European Drive Cycle. Currently, Euro 6 light duty vehicles must ensure that emissions do not exceed $0.08 \mathrm{~g} / \mathrm{km}$ for NOx during NEDC and the proposed WLTP tests. Despite this there is a significant discrepancy between real world driving and current NEDC emissions, which is approximately 2.8 for EURO 6. The permitted conformity factor between the new WLTP real-world emissions will be 2.1 (from 2017) and 1.5 from 2019.

There are many uncertainties about the benefits of the new Real-world Driving Emission (RDE) standard, but in any event the true benefits will not be known with confidence until the early 2020s. The benefit of the vehicle fleet turning over to vehicles meeting the RDE requirements will not be realised fully until after 2030. Therefore, it is unlikely these Euro $6 \mathrm{RDE}$ vehicles will improve air quality materially until the mid-2020s at the earliest.

At present, the Euro emission standards apply only to new vehicles and there is no means of monitoring the performance of the emission control system on a vehicle over its lifetime with regard to NOx. The RDE legislation will require that emissions are within the standard for the first $160,000 \mathrm{~km}$ or five years, whichever is the earlier. However, there are currently no compliance tests planned once the car is in service. 


\subsubsection{Vehicle fleet dynamics}

The Draft AQP set out a number of assumptions surrounding vehicle fleet turnover. In particular, the Draft AQP assumed a vehicle fleet turnover of $25 \%$ following the declaration of a CAZ (discussed below). However, Chatterton [16] noted that there was insufficient clarity on the validity of this assumption. An explanation of the determination of fleet turnover is set out in Section 5.2 of Defra's Technical Report, however it does not expand on that presented in the Draft AQP.

Chatterton also noted that the information relating to vehicle fleet dynamics in Defra's plans, including for Clean Air Zones (CAZs), lacked sufficient detail to determine whether the conclusions of the subsequent modelling were robust. Furthermore, there was neither clear detail on how the CAZs will influence either overall fleet dynamics or particular vehicle groups (cars, LGVs, HGVs, buses and coaches). And neither was the plan considered to be transparent as to the proportion of pollution that various groups and ages of vehicles are currently responsible for, and how this was expected to change under the plans. A number of key issues were identified by Chatterton:

- Deficiencies in the description or provision of data within the report, and ambiguity and lack of transparency, make the report inadequate for proper understanding and not of a standard that would be expected for this type of study (compared, for example, with previous such assessments undertaken for the London Low Emission Zone) given the importance of the Government's Air Quality Plan;

- No consideration of distances travelled by different vehicle classes, or the amount of pollution each group is responsible for;

- Inadequate consideration of how both mileages in/outside CAZs and responses to the scheme will differ between different types of vehicle owner;

- Unsupported assumptions regarding scrappage rates and vehicle upgrading;

- Potentially Erroneous assumptions about effort and cost incurred by vehicle owners in upgrading vehicles in response to the CAZs.

Together, these issues indicate a great deal of uncertainty about the current understanding of the baseline vehicle fleet and how this is contributing to the air quality problem. And critically, the effect that vehicle fleet turnover assumptions have within the SL-PCM model is unclear.

\section{Clean Air Zones}

A key part of the government's approach to reduce pollution in towns and cities across the UK is the designation of Clean Air Zones in Birmingham, Leeds, Nottingham, Derby and Southampton by 2020. As shown in Table 1, vehicle restrictions will apply in each CAZ but in those CAZ designated outside London, private cars will not be restricted. Although only a few CAZ have been designated, other towns and cities are encouraged by Defra to develop their own. 
Table 1: Clean Air Zone Classes from the Clean Air Plan.

\begin{tabular}{|c|c|}
\hline Clean Air Zone class & Vehicles included \\
\hline A & Buses, coaches and taxis ${ }^{23}$ \\
\hline B & $\begin{array}{l}\text { Buses, coaches, taxis and heavy goods vehicles } \\
\text { (HGVs) }\end{array}$ \\
\hline C & $\begin{array}{l}\text { Buses, coaches, taxis, HGVs and light goods } \\
\text { vehicles (LGVs) }\end{array}$ \\
\hline $\mathrm{D}$ & Buses, coaches, taxis, HGVs, LGVs and cars \\
\hline
\end{tabular}

Globally, vehicle restrictions have often resulted in a reduction in air pollution, however those restrictions that do not include private cars have been shown to be ineffective [17]. Whilst the underpinning framework and principle of CAZs has merit, the likelihood that the CAZ set out within the plan will reduce air pollution significantly is disputed.

\section{Discussion}

The robustness of the AQP has been called into question since it was published in January 2016 and a broad consensus amongst the air quality community is that these plans are not sufficient to address the public health challenge in as short a time as possible [18]. The lack of transparency within the consultation process, particularly regarding the data used to estimate the rate of vehicle fleet turnover reduces the confidence of stakeholders in the robustness of the plan. It is also concerning that a widely held view of a lack of transparency within the plan was not properly reported in the summary of consultation responses and raises the possibility that these widely held views have not been considered thoroughly in the final AQP.

As set out above, a number of assumptions have been made within the AQP which give rise to concerns that the compliance dates set out within the plan are unrealistic. Multiple studies analysing vehicle emission factors consider them to be significantly underestimated within COPERT, which is used in the AQP. The Alternative Scenario within the AQP which considered the implications (albeit briefly) of vehicle emissions being five times higher than type approval would be more representative of compliance and as such, in line with Defra's own prediction, only 8 additional zones and agglomerations will achieve compliance by 2020 , leaving 30 non-compliant.

In addressing the likely impact of RDE, TNO note that the benefit of these changes in vehicle emissions permeating the vehicle fleet are not likely to be felt until the mid-2020s at the earliest and as such their benefit in the short-term for achieving compliance is likely to be minimal. These vehicles will be required to ensure emissions do not exceed type approval (plus real-world conformity) for at least 5 years, however, considering that a car's typical lifespan is 16 years there 
will be a period of more than 10 years when cars could legally be operating in a degraded state, emitting significantly more NOx.

Individually, each of these assumptions is significant, however the lack of transparency within the plan makes it difficult to assess their exact impact. Despite this, the considerable evidence presented above, coupled with Defra's own analyses, are sufficient to consider that compliance will not be achieved by 2020 in over 30 zones and agglomerations and that compliance beyond 2025 is considerably more realistic. For London, compliance by 2030 is more probable.

On the $28^{\text {th }}$ of April, 2016, a High Court judge gave ClientEarth permission to seek a judicial review of Defra's actions on the basis that they believe the government has not demonstrated that it has used its powers to full effect within the AQP to reduce air pollution in line with the initial Supreme Court judgement [19].

The evidence and issues discussed here may serve to reinforce the concerns that the current AQP is not fit for purpose and must be reviewed and updated with demonstrable, short- and long-term strategies for reducing air pollution as soon as possible.

\section{Conclusion}

This contribution has reviewed new evidence pertaining to the transparency, openness and robustness of the data underpinning compliance within Defra's air quality plan [8]. A lack of transparency during the consultation process was prominent in several studies reviewed and evidence from multiple other studies has pointed to a distinct difference between Defra's estimated dates of compliance and that supported by a review of the literature. Compliance is not expected to be achieved within the government's timescales and significant additional action is required on the ground to reduce air pollution, a public health emergency, to within limits in as short a time as possible.

\section{References}

[1] Vidal, H. Helm, T (2016) Shock figures to reveal deadly toll of global air pollution. Available from: http:/www.theguardian.com/environment/2016/ jan/16/world-heslth-organisation-figures-deadly-pollution-levels-worldbiggest-cities [accessed 18th January, 2016].

[2] World Health Organisation Executive Board (2014) Health and the environment: addressing the health impact of air pollution. Available from: http://apps.who.int/gb/ebwha/pdf_files/EB136/B136_15-en.pdf

[3] European Environment Agency (2015) Air quality in Europe - 2015 report. Publications Office of the European Union. Luxembourg.

[4] Gowers, A.M, Miller, B.G, Stedman, J.R. (2014) Estimating Local Mortality Burdens associated with Particulate Air Pollution. Public Health England, Oxfordshire.

[5] Air quality guidelines for Europe. Copenhagen, WHO Regional Office for Europe, 1987 (WHO Regional Publications, European Series, No. 23). 
[6] Chatterton, T., Longhurst, J., Leksmono, N., Hayes, E. T. and Symonds, J. (2007) Ten years of Local Air Quality Management experience in the UK: An analysis of the process. Clean Air and Environmental Quality, 41 (4). pp. 26-31.

[7] UK Supreme Court (2015) R (on the application of ClientEarth) (Appellant) v Secretary of State for the Environment, Food and Rural Affairs (Respondent) [2015] UKSC 28 On appeal from [2012] EWCA Civ 897.

[8] Air quality in the UK: plan to reduce nitrogen dioxide emissions (2015) Available from: (https://www.gov.uk/government/publications/air-qualityin-the-uk-plan-to-reduce-nitrogen-dioxide-emissions) [accessed on 9th May, 2016].

[9] Barnes, J. (2016) Independent review of responses to the Defra Draft Air Quality Plan consultation. Consultancy Report for Gatwick Airport Ltd.

[10] Department for Environment, Food and Rural Affairs. (2016) Summary of responses to the government's consultation on draft air quality plans.

[11] Air modelling for Defra (2015) Available from: (https://ukair.defra.gov.uk/research/air-quality-modelling?view=modelling) [accessed on 10th May 2015].

[12] Michel Vedrenne, Cooke, M., Stedman, J. R., Kent, A.J. (2015) Streamlined PCM Technical Report: Report for Department for Environment, Food \& Rural Affairs (project AQ0959).

[13] Gatwick Airport Ltd. (2016). A second runway for Gatwick: Air Quality Projections in the London Air Quality Plan. Annex 4.

[14] Gatwick Airport Ltd. (2016). A second runway for Gatwick: Air Quality Projections in the London Air Quality Plan. Annex 5.

[15] Williams, B (2016). A Technical Review of the Soundness of the Department for Environment, Food and Rural Affairs' Final Air Quality Plan. Consultancy Report for Gatwick Airport Ltd.

[16] Chatterton, T (2016) A Review of the Incorporation of Vehicle Fleet Dynamics within Defra's Final Air Quality Plan. Consultancy Report for Gatwick Airport Ltd.

[17] Holman C, Harrison R, Querol X. (2015). Review of the efficacy of low emission zones to improve urban air quality in European cities. Atmospheric Environment. 111: 161-169

[18] Air Quality Bulletin (2015), 116: 8-11.

[19] Queen's Bench Division Administrative Court (2016) In the matter of an application for Judicial Review, The Queen on the application of ClientEarth (No 2) versus Secretary of State for Environment, Food and Rural Affairs. CO Ref: CO/150812016. 